\title{
Rehabilitación protésica de un niño de 3 años con Displasia ectodérmica hipohidrótica
}

\section{Resumen}

La Displasia Ectodérmica Hipohidrótica (DEH) o síndrome de Christ-Siemens-Touraine, es una rara enfermedad de carácter congénito, siendo afectado uno o varios componentes del tejido ectodérmico. Caracterizado por hipohidrosis, hipotricosis e hipodoncia. La mayoría de los casos se relaciona con una herencia recesiva ligada al cromosoma $X$, afectándose por consiguiente en los varones, pero también existen otras formas de herencia autosómica dominante y rece- siva. Se presenta el caso clínico de un niño de 3 años 5 meses con oligodoncia y reabsorción de los procesos alveolares por ausencia total de las piezas deciduas, por lo que se realiza la rehabilitación protésica con prótesis total removible, como resultado se logra aumento de la dimensión vertical, mejora de la fonación, masticación, habla y la autoestima del paciente.

Palabras clave: displasia ectodérmica hipohidrótica, prótesis parcial removible, hipodoncia, oligodoncia.

Relato de caso

\section{Reabilitação protética de uma criança de 3 anos com displasia ectodérmica hipoidrótica}

\section{Resumo}

A Displasia do Ectodérmica Hipoidrótica (DEH) ou síndrome de Christ-Siemens-Touraine, é uma doença rara de caráter congênito, sendo afetado um ou vários componentes do tecido ectodérmico. Caracterizada por hipoidrose, hipotricose e hipodontia. A maioria dos casos relaciona-se com uma herança recessiva ligada ao cromossoma X, afetando, portanto, homens, no entanto, também existem outras formas de herança autossômica dominante e recessiva. Este trabalho apresenta o caso clínico de um menino de 3 anos 5 meses com oligodontia e reabsorção dos processos alveolares por ausência total dos elementos dentais decíduos, pelo que se realizou a reabilitação protética com prótese total removível. Como resultado se obteve aumento da dimensão vertical, melhora na fonação, mastigação, fala e autoestima do paciente.

Palabra chave: displasia ectodérmica, reabilitação bucal, prótese parcial removível, hipodontia, oligodontia. 
Case report

\section{Prosthetic rehabilitation of a 3 year old child with Hypohidrotic Ectodermal Dysplasia}

\begin{abstract}
Hypohidrotic ectodermal dysplasia (DEH) or Christ-Siemens-Touraine Syndrome is a rare congenital disease, in which is affected one or more ectodermic tissue components and is characterized by hypohidrosis, hypotrichosis and hypodontia. Most cases are associated with X-linked recessive heredity, thus affecting in males, but there are other forms of dominant and recessive autosomal heredity. We report the case of a child of 3 years 5 months with oligodontia and resorption of alveolar processes by absence of deciduous teeth, so that makes prosthetic rehabilitation with removable full dentures, as a result is achieved an increasing of the vertical dimension, improved phonation, mastication, speech and self-esteem.
\end{abstract}

Key words: Hypohidrotic ectodermal dysplasia, prosthetic rehabilitation, partial dentadure, hypodoncia, oligodontia.

\section{Introducción}

La displasia ectodérmica Hipohidrótica (DEH) o síndrome de Christ-Siemens-Touraine, es una enfermedad genética recesiva ligada al cromosoma $X$, se describe un amplio grupo de alteraciones de la organización celular en al menos dos tejidos derivados de la capa embrionaria ectodérmica. En 1994 se clasificaron las displasias ectodérmicas en 154 síndromes y 11 subgrupos según la afectación clínica; estimándose su frecuencia en 7 por cada 100,000 recién nacidos. $(1,2,3,4)$
La DEH se clasifica en anhidrótica e hipohidrótica anhidrótica es una forma autosómica dominante, sus manifestaciones son aplasia de glándulas sudoríparas, ausencia de glándulas sebáceas, pelo rubio, fino y escaso, falta de pestañas y cejas, pocos dientes y suelen tener forma cónica. El tipo hipohidrótico se caracteriza por hipotricosis (vello y pelo escasos), hipoplasia malar, puente nasal ancho, labios invertidos, piel periorbital hiperpigmentada, orejas de inserción baja, piel delgada y múltiples dientes anteriores de forma cónicos y espaciados. $(3,12)$

Se hereda de forma autosómica dominante, autosómica recesiva o ligada al cromosoma $X$, el gen responsable esta en las mujeres quienes son las portadoras; y padecen la enfermedad los hombres. El gen responsable se localiza en el locus q12-q13.1 del cromosoma $X$, constando de 12 exones, siendo ocho de ellos encargados de codificar una proteína trasmembrana (EDA-A) involucrada en el desarrollo ectodérmico, cuyas mutaciones originan la patología que caracteriza el síndrome y raramente se presenta con un patrón autosómico recesivo. $(2,4,5,7)$

Fue descrito por Thurnam por primera vez en el año 1848, presentando dos casos; se caracterizó por la triada hipotricosis (anomalías en piel, pelo y uñas), hipodoncia ó anodoncia e hipohidrosis (ausencia parcial o total de glándulas sudoríparas Ecrinas) y algunos rasgos como: abombamiento de la frente, nariz en silla de montar, labios evertidos, puente nasal aplanado, arcadas supraorbitales, hipopigmentación periorbitaria y pabellones auriculares prominentes con im- 
plantación baja, los dientes anteriores pueden ser cónicos. $(3,5)$

Otras alteraciones son: déficit de secreción lagrimal, con subsiguiente fotofobia y conjuntivitis; rinitis atrófica con formación de costras y anosmia; distrofia ungueal con uñas cóncavas; y anomalías en las glándulas mamarias; hipomastia, amastia, hipotelia, atelia. (4)

El diagnóstico de la Displasia Ectodérmica Hipohidrótica DEH debe ser documentada por una biopsia de piel para determinar la disminución o ausencia de sudoración. (3) En el lactante se debe prestar atención a la fiebre de origen desconocido. (4)

El diagnóstico diferencial de las displasias ectodérmicas se debe realizar con patologías como: la aplasia de cutis congénita, la disqueratosis congénita, la fiebre de origen desconocido o síndromes progeroides, como el síndrome de Werner o el de Rothmund - Thompson. También se puede realizar el diagnóstico pre natal de forma invasiva (biopsia de piel fetal o estudio genético de vellosidades coriónicas) o no invasiva, mediante ultrasonografía tridimensional identificando las características faciales a partir de la $30^{a}$ semana de gestación. $(2,8)$

El tratamiento médico consiste en la protección a la exposición de altas temperaturas hidratando la piel y mucosas, con productos emolientes e hidratantes. El uso de lágrimas artificiales previene el daño corneal, en la nariz suero fisiológico o pomadas nasales vitamínicas, la utilización de ropa húmeda si se practica deporte, uso de corticoides tópicos en casos de lesiones irritativas o dermatitis atópica. $(2,3,4,6)$

El tratamiento odontológico debe ser de acuerdo a la gravedad del caso, de acuerdo a la edad y desarrollo dental. El tratamiento protésico es importante por razones fisiológicas, emocionales y psicosociales; pudiendo instalar prótesis fijas, removibles o soportadas por implantes. El inicio del tratamiento protésico se debe realizar lo más temprano posible, para limitar la reabsorción de los procesos alveolares. $(2,3)$

\section{Relato de Caso}

Paciente de 3 años 6 meses de edad,género masculino, nacido de parto por cesárea por presentar taquicardia fetal, peso al nacer 3600 gr., talla $47 \mathrm{~cm}$., presentó neumoia al mes de nacido y diarrea a los 10 meses por lo que fue hospitalizado. El niño muestra caracteristicas faciales de Displasia ectodermica hipohidrotica (Figura 1).

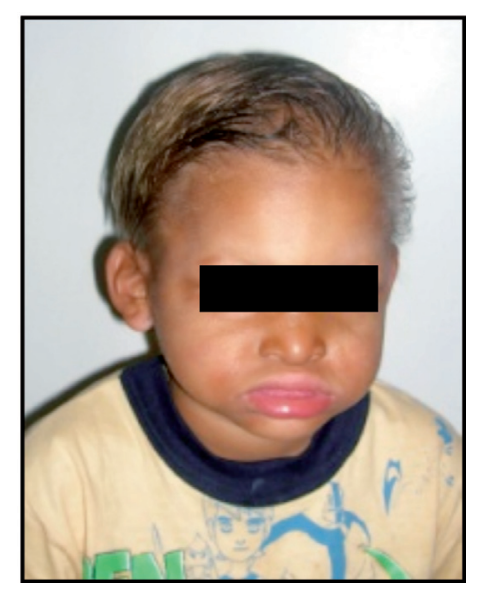

Figura 1. Características faciales de Displasia Ectodérmica Hipohidrótica.

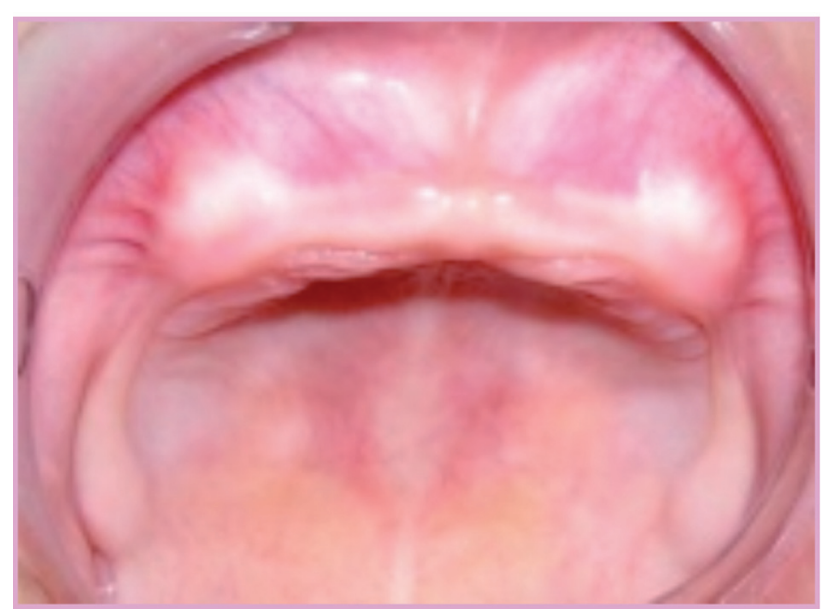

Figura 2. Maxilar superior edéntulo total, con reborde tipo irregular. 
En boca presenta oligodoncia total de la dentición decidua tanto en el maxilar superior como en la mandíbula (Figura 2 y 3 ).

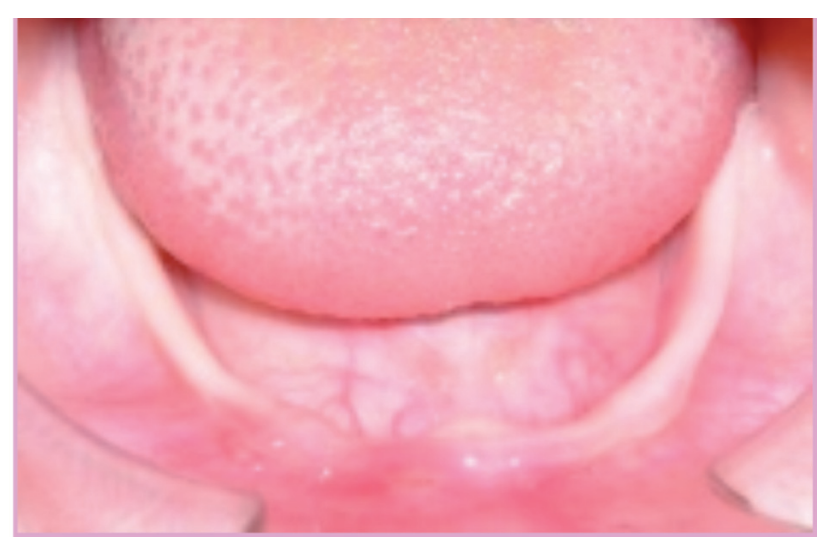

Figura 3. Anodoncia total maxilar inferior, con reborde tipo regular.

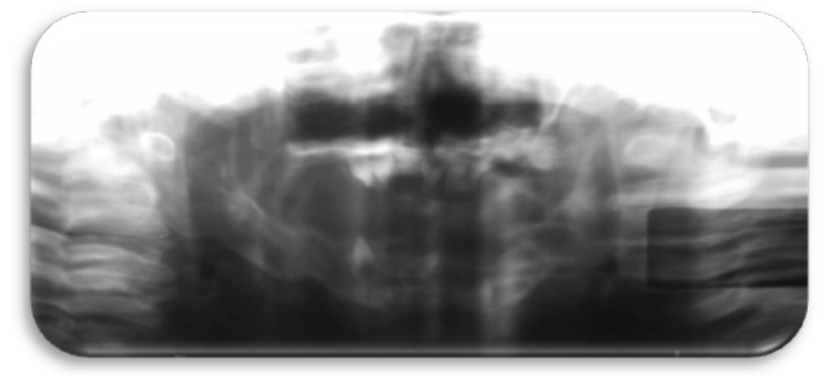

Figura 4. Ausencia de las piezas dentales deciduas en la arcada superior y en la arcada inferior, y se evidencia las piezas 12, 11, 21 y 22 en forma de clavija.

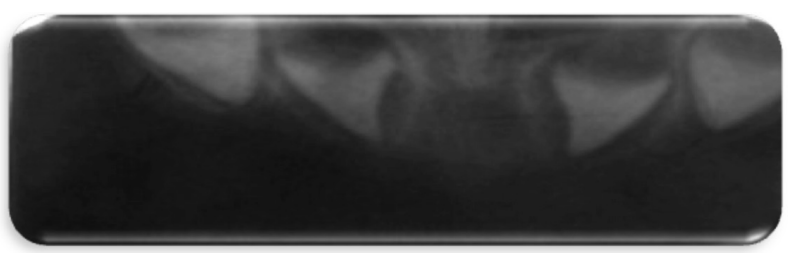

Figura 5. Presencia de los gérmenes dentarios de las piezas 12, 11, 21 y 22 en forma de clavija.
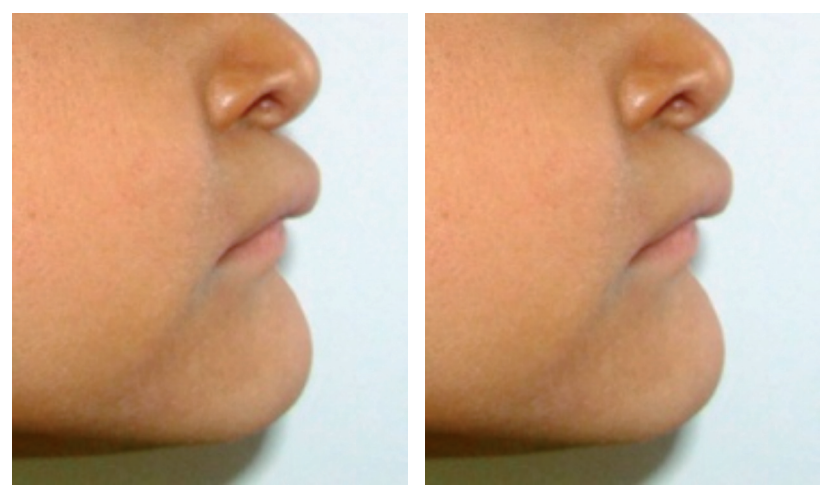

Figura 6. Pérdida de la di- Figura 7. Aumento de la dimensión vertical. mensión vertical.
El examen radiográfico muestra la ausencia de las piezas dentales deciduas en el maxilar superior e inferior, y se visualiza las piezas 12, 11, 21 y 22 en forma de clavija. Se plantea el tratamiento en la fase rehabilitadora que acompañe el desarrollo y crecimiento del niño (Figura 4 y 5).

El tratamiento consistió en rehabilitar al niño con la confección de una prótesis total en el maxilar superior y en maxilar inferior. La impresión de los rebordes alveolares se realizó con material hidrocoloide en una cubeta universal $n^{\circ} 3$, sobre el modelo de trabajo se diseña y confecciona la prótesis total removible siguiendo un procedimiento semejante a la de un adulto.

Se logró aumento de la dimensión vertical con mejoramiento en la fonación, masticación, habla y autoestima del paciente pediátrico.

\section{Procedimiento}

- Seleccionar cubetas de impresión (fig. 8).

- Toma de impresión primaria de ambos maxilares.

- Identificar las estructuras anatómicas del modelo desdentado.

- Confeccionar las cubetas individuales en ambos maxilares.

- Toma de impresión de modelos definitivos o modelos de trabajo.

- Confección de placas bases y rodetes de oclusión-contorno.

- Prueba de rodetes en boca: borde inferior del rodete a $1 \mathrm{~mm}$ por debajo de borde labial y manteniendo la dimensión vertical de 40 $\mathrm{mm}$. 


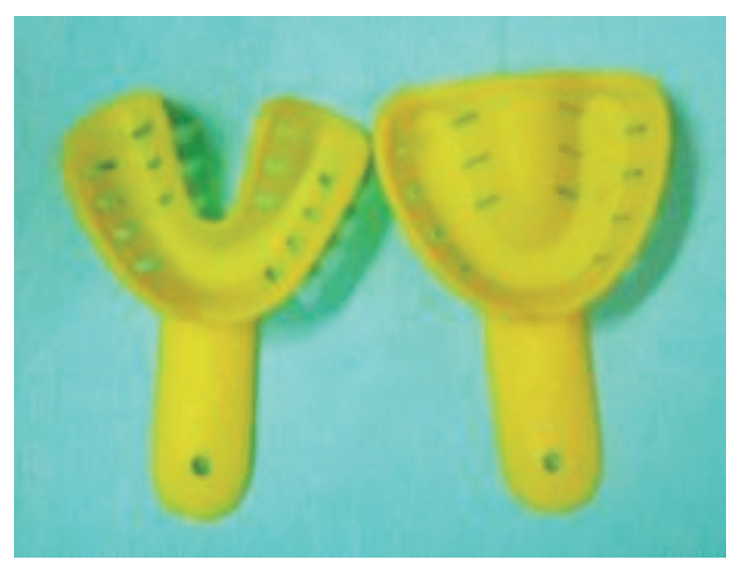

Figura 8. Cubetas de impresión.

- Montaje en el modelos en articulador de Bisagra (3).

- Enfilado de dientes artificiales para niños (diferentes marcas):

- Stardent ${ }^{\circledR}$ (superior: \#59, inferior: \#61 y 62).

- Olympic® (dientes anteriores superior e inferior; \#222 color 62, dientes posteriores; superior e inferior \#PDS, color 62).

- VIPI DENT Plus® (dientes superiores: anteriores \#10 color A2, posteriores \#30M color A2, dientes inferiores: anteriores \#3M color A2, posteriores \#30M color A2).

- Encerado y tallado de las bases; dando forma, volúmen y caracterizaciones a la encía protética y a las futuras bases de las dentaduras. Permitiendo que la lengua, labios y carrillos se adapten a las superficies vestibular y palatina ó lingual correctamente contorneadas, mejorando la estabilidad y retención de las prótesis.

- Procesado: Procedimiento por el cual se reemplaza la placa base y encerado por un

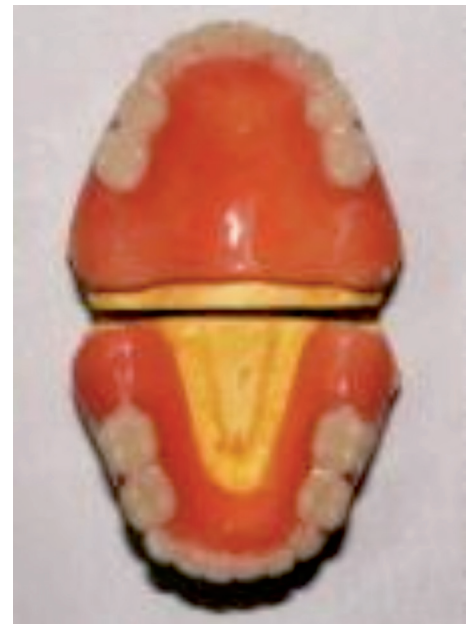

Figura 9. Aspecto final de la prótesis acrilizada.

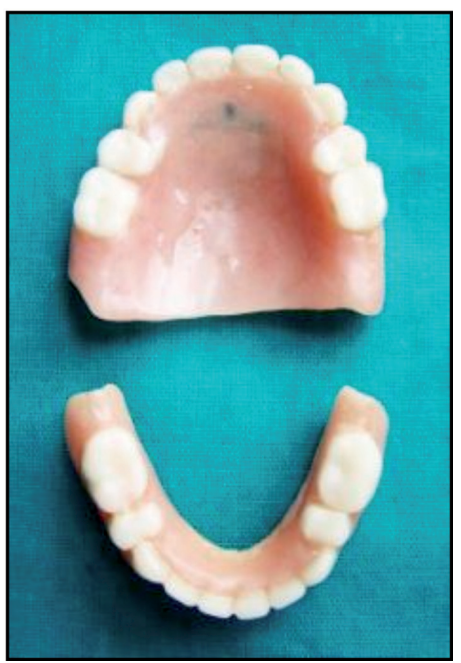

Figura 10. Prótesis total confeccionada.

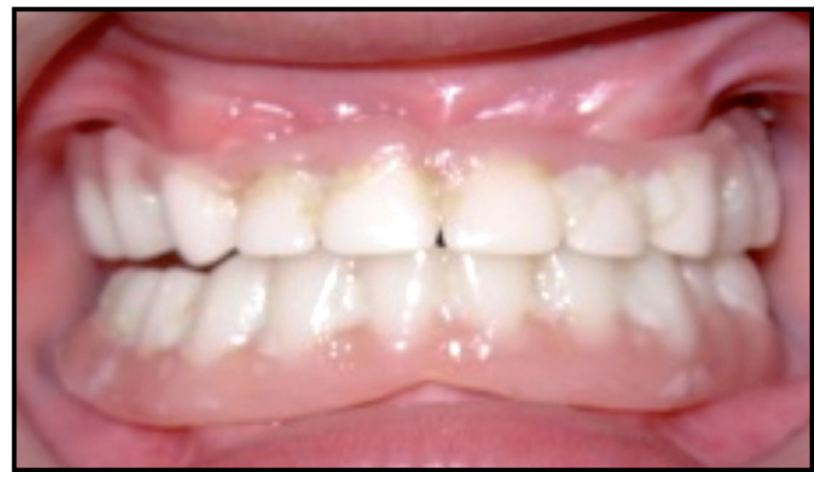

Figura 11. Aspecto final con prótesis instalada.

material plástico, duro y pulible. Este procedimiento consta de cinco etapas:

- Enmuflado.

- Eliminación de cera. 
- Empaquetado.

- Polimerización del acrílico.

- Desenmuflado.

- Remontaje y ajuste oclusal: Se reposiciona los modelos definitivos al artículador con las dentaduras procesadas, el objetivo es realizar ajuste aclusal para corregir pequeños cambios en la dimensión vertical originado durante el procesado.

- Acabado: primero se eliminan los excesos del acrilizado para luego alisar y pulir solamente las superficies externas de las prótesis. (11)

\section{Discusión}

El síndrome de DEH está en general ligada al cromosoma $\mathrm{X}$, las mujeres son portadoras del gen responsable, y los hombres sufren de la enfermedad. Las madres por lo general tienen cierta característica típica de la enfermedad y, a veces en forma autosómica recesiva. En la actualidad, la DEH está relacionada con una mutación de la proteína ectodisplasina-A, relacionado con el gen de la EDA en el q12- q13 locus del cromosoma X. (3)

El paciente presenta manifestaciones orales propias del síndrome: frente amplia, puente nasal aplanado, nariz pequeña con alas hipoplásicas, labios prominentes; hipopigmentación periorbitaria y pabellones auriculares prominentes con implantación baja. La piel del resto del cuerpo es seca e hipopigmentada. El pelo es fino, seco e hipocrómico; hay hipoplasia o ausencia de las glándulas sudoríparas y sebáceas.

Diversos autores han propuesto la rehabilitación protésica como tratamiento de elección para este tipo de pacientes. Se recomienda el uso de prótesis removibles durante las primeras etapas de crecimiento (3-5 años), permitiendo el ajuste de la dimensión vertical y una mejor interrelación de los maxilares. (5)

El tratamiento rehabilitador permite de una manera relativamente fácil, aceptable, rápida y económica: dar una solución a la función masticatoria, estética y del desarrollo psicológico del niño.

\section{Conclusión}

Los niños con D. E. H., presentan alteraciones dentarias de forma y número, por lo que presentan anodoncia total o parcial de las piezas dentarias, a los pacientes con ausencia total de piezas dentarias es oportuno confeccionarles una prótesis total de acrílico para el maxilar superior e inferior; que va ha mejorar la función masticatoria, la estética, la fonética con lo que el niño tendra una vida social adecuada que le permita desarrollarse adecuadamente. La utilización de la prótesis de acrílico Ayudara a normalizar el desarrollo de los músculos masticatorios y periorales, en consecuencia, el patrón de crecimiento de los huesos basales.

El tratamiento protésico debe hacerse de una forma individualizada y siempre a partir de un encerado de estudio que busque una buena estabilidad oclusal. Debe iniciarse lo más precozmente que se pueda, para evitar en lo posible la reabsorción y atrofia de los procesos alveolares y controlar la dimensión vertical que se puede ver gravemente afectada ante la falta total o parcial de dientes. (5)

\section{Recomendación}

Es muy importante rehabilitar a los niños con DEH lo más temprano posible para devolver 
las funciones disminuidas como: aumento de la dimensión vertical con mejoramiento en la fonación, masticación, habla y autoestima en el paciente pediátrico.
Se debe realizar controles periódicos luego de la rehabilitación protésica del niño debido al crecimiento y desarrollo constante de los maxilares y erupción de los dientes permanente que puede ocasionar desadaptaciones en la prótesis.

\section{Referencias}

1. Gonzales J, Galera H, Muñoz F. Manifestaciones ORL de la displasia ectodérmica Hipohidrótica. Acta Otorrinolaringol Esp 2005; 55; 176-178.

2. Campuzano S, Santos J, Medina A, Sánchez J. Displasia ectodérmica Hipohidrótica. An Pediatr (Barc) 2005; 62 (4); 393-4.

3. Cadena A, García G, Sosa-de-Martinez C, Teja E. Manejo estomatológico de una paciente con displasia ectodérmica Hipohidrótica. Acta Pediatr Mex 2006; 27(2); 96-100.

4. Cruz M, Bosch J. Atlas de Síndromes pediátricos. ESPAXS. S. A. 1998. Pág. 40.

5. Pipa A, López-Arranz E, Gonzales M. Tratamiento odontológico en la displasia ectodérmica. Actualización. AVANCES EN ODONTOESTOMATOLOGÍA Vol. 22 - Núm. 3 - 2006.

6. Alarcón R, Ramírez P, Yañez T, Alárcon F, Solís F. Displasia ectodérmica Hipohidrótica, a propósito de un caso. Dermatol Pediactr Lat Vol 4 No 3, 2006.

7. García J, Sánchez V. Displasia Ectodérmica Hipohidrótica (anhidrótica). Archivos de Investigación Pediátrica de México Vol. 4 No 13 Abril/Junio 2001.

8. Avilés J, Hernanz J, Huerta M. Displasia ectodérmica. Acta Pediatr Esp 2003; 61: 474-5

9. Sepúlveda W, Sandoval R, Carsten E, Gutiérrez J, Vásquez P. Hypohidrotic ectodermal dysplasia: Prenatal diagnosis bythree-dimensional ultrasonography. J Ultrasound Med. 2003; 22:731-5.

10. Vargas GA. Reduced epidermal growth factor receptor expression in hypohidrotic ctodermal dysplasia and Tabby mice. J Clin Invest. 1996;97:2426-32

11. Manual de Procedimientos de Laboratorio. Prótesis Total. Universidad Peruana Cayetano Heredia. Facultad de Estomatología. Sección de Oclusión 1996.

12. Ponce S, Ledesma C, Morales I, Garcés M. Síndromes vinculados con la anodoncia. Revista ADM 2010; 67 (2); $62-64$.

13. Vera A, Bustos I, Castro R. Rehabilitación Protésica en Odontopediatría: Reporte de Tres Casos Clínicos. Revista Dental de Chile. 2003; 94 (3); 13-17.

14. Tallon V, Artells R, Navarro A, Carvalho P, Belmonte A, Serra I, Monzó M, Manzanares C. Transtornos genéticos asociados a las alteraciones del número de los dientes. Estado de la cuestión. DENTUM 2004; 4(3); 88; 94.

15. Millares W, Munive F. Historia Clínica Práctica para el desdentado Completo. La Carta Odontológica. Vol. 3 No $11 /$ Ene. Dic 95. Pág. 11-17.

Texto traducido por: Fabián Calixto Fraiz

Recibido: 27-10-2011

Aceptado: 06-01-2012

Correspondencia: dentalmarquez@yahoo.es 